\title{
PEMANFAATAN JENIS TUMBUHAN SEBAGAI OBAT TRADISIONAL BERBASIS ETHNOMEDICAL KNOWLEDGE PADA MASYARAKAT SUKU MANDOBO
}

\section{(The Use of Plant Species for Traditional Medicine Based on Ethnomedical Knowledge of Mandobo Tribal Community)}

\author{
Mikaela Mikan $^{1}$ dan Yubelince Y. Runtuboi ${ }^{1 凶}$ \\ Jurusan Kehutanan, Fakultas Kehutanan Universitas Papua Manokwari, Papua Barat, \\ 98314. Tlp/Fax: +62986211065. \\ ${ }^{\square}$ Penulis Korespondensi: Email: runtuboi.ketty@yahoo.com \\ Diterima: 12 Feb 2019| Disetujui: 17 Mar 2019
}

\begin{abstract}
Abstrak
Penelitian ini bertujuan untuk mengetahui jenis-jenis tumbuhan yang dimanfaatkan sebagai sumber alternatif obat berbasis pengetahuan lokal masyarakat suku Mandobo di Kampung Sokanggo. Metode yang digunakan dalam penelitian ini adalah metode desktiptif dengan teknik wawancara kepada responden yang dipilih. Hasil penelitian menunjukkan bahwa ketergantungan masyarakat terhadap tumbuhan obat cukup tinggi dengan dimanfatakannya 25 jenis tumbuhan dari 20 famili yang meliputi jenis rumput, perdu, liana dan pohon. Famili yang sering dimanfaatkan antara lain Zingiberaceae, Moraceae, Lamiacea. Bagian daun menjadi bagian utama dari tumbuhan yang sering dimanfaatkan yakni sebanyak 12 spesies. Sementara cara pengolahan yang umum digunakan adalah melalui perebusan. Proses pemanfaatan tumbuhan hutan dalam komunitas masyarakat suku Sokanggo sangat efektif dalam menyembuhkan penyakit-penyakit umum yang diderita di dalam komunitas mereka.
\end{abstract}

Kata kunci: tumbuhan hutan, tanaman obat, pengetahuan lokal, masyarakat lokal, penyakit

\begin{abstract}
This study focuses on perceiving the use of various forest vegetation for medical alternative treatments that based on local knowledge from Mandobo tribe in Sokanggo village. The study has applied descriptive method through interview technique to deliberately chosen respondents among individuals in the community. The result noticed that the community has been mostly lied on forest vegetation for multiple medical treatments with the total forest vegetation of 25 that came from 20 families which cover grasses, herbaceous plant, liana, and trees. The most used plant families were Zingiberaceae, Moraceae, and Lamiacea. Leaf has been the most preferred part from the plant compared to others for medicine with 12 species. In terms of the process, boiling was preferred compared to other techniques. So far, the way local community consume medicinal-based plants in their pathway has been effective in dealing with various common diseases occurred in their community.
\end{abstract}

Keywords: forest vegetation, medicinal plant, local knowledge, local community, disease 


\section{PENDAHULUAN}

Paradigma kesehatan saat ini adalah 'back to nature' dengan penggunaan bahanbahan alami sebagai pilihan untuk mengatasi masala-masalah kesehatan. Masyarakat menyadari bahaya jangka panjang yang timbul sebagai akibat mengkonsumsi obat-obatan yang terbuat dari bahan kimia. Disisi lain sejarah menyatakan bahwa sebelum ilmu kedokteran dan peralatan berkembang, manusia sudah berusaha mencari penyembuhan penyakit dengan memanfaatkan bahan-bahan alam yang ada disekitarnya, berupa akarakaran, daun-daunan, serta bagian tumbuhan yang lainnya. Pemanfaatan bagian tumbuhan obat telah berlangsung secara turuntemurun sehingga melahirkan pengetahun etnis tertentu terhadap obat-obat tradisional (Muller 2005).

Papua memiliki keanekaragaman flora dan fauna yang tinggi, namun pemanfaatannya masih terbatas. Hal ini disebabkan oleh kurangnya kajian terhadap jenis obat yang sudah dimanfaatkan oleh suku-suku di Papua. Padahal keberadaan suku-suku di Papua telah memanfaatkan tumbuh-tumbuhan untuk untuk berbagai tujuan secara turuntemurun bahkan telah mengadopsi pengetahuan dari luar. Menurut Muller (2005), orang Papua memanfaatkan 650 jenis tumbuhan, 134 famili dan 378 genera sebagai obat, bahan tali-temali, bahan membuat perahu, bahan ukiran dan bahan makanan. Fakta menunjukkan bahwa masyarakat tradisional telah mampu memanfaatkan aneka jenis tumbuhan untuk tujuan pengobatan secara turun-temurun walaupun data ilmiah tentang bahan obat ini belum di ungkapkan secara jelas (Cabuy et al. 2012).
Dalam upaya mencapai hidup sehat, pemerintah menyelenggarakan upaya kesehatan dengan melibatkan peran aktif masyarakat. Salah satu kegiatan adalah pengobatan tradisional. Kegiatan ini sekaligus membantu meringankan beban pemerintah dalam upaya pelayanan kesehatan masyarakat (Wowor dkk. 2016). Pengobatan tradisional secara langsung atau tidak langsung berhubungan dengan upaya pemanfaatan dan pelestarian sumberdaya hayati, khusus tumbuhan obat. Pengetahuan tentang pemanfaatan tumbuhan dapat diperoleh dari pemanfaatan individu yang diwariskan dari generasi ke generasi sehingga menjadi pengetahuan penduduk lokal dalam mengidentifikasi tumbuhan tumbuhan obat dari hutan secara alami. Langkah awal dalam pengembangan pemanfaatan dan pelestarian tumbuhan obat adalah dengan mendokumentasikan pengetahuan penduduk lokal mengenai pemanfaatan tumbuhan obat diberbagai daerah di Papua pada umumnya dan khususnya di daerah Boven Digoel, Kampung Sokanggo. Tujuan dari penelitian ini ialah untuk mengetahui jenis-jenis tumbuhan bahan obat, mengetahui bentuk-bentuk pemanfaatan tumbuhan, dan memahamai pola transfer pengetahuan pemanfaatan tumbuhan oleh masyarakat Kampung Sokanggo.

\section{METODE PENELITIAN}

Penelitian ini di laksanakan di Kampung Sokanggo Distrik Mandobo Kabupaten Boven Digoel selama 2 minggu mulai pada tgl $17 \mathrm{~s} / \mathrm{d} 29$ Juli tahun 2014. Subyek dalam penelitian ini adalah masyarakt suku Mandobo yang memanfaatkan tumbuhan sebagai bahan obat-obatan. Obyek yang diamati dalam penelitian ini adalah jenis tumbuhan yang 
dimanfaatkan sebagai bahan obatanobatan tradisional oleh suku Mandobo di kampung Sokanggo Distrik Mandobo kabupaten Boven Digoel. Penelitian ini menggunakan metode deskripsi dengan teknik observasi lapang dan wawancara semi stuktural.

\section{Penentuan responden}

Penentuan responden dilakukan secara sengaja (purposive) yaitu dengan memilih responden yang terlibat secara langsung dalam pemanfaatan obat tradisional. Selanjuntya responden ini kemudian diwawancara dengan mengacu pada kuisioner yang telah disiapkan. Jumlah responden yang diwawancarai adalah sebanyak 6 orang dari $58 \mathrm{KK}$ di Kampung Sokanggo distrik Mandobo kabupaten Boven Digoel.

\section{Tahapan Penelitian}

Penelian ini dilaksanakan dengan mengikuti langkah-langkah sebagai berikut :

1. Survei awal

Survei awal dilakukan pada 2 lokasi yaitu pada hutan primer dan sekunder sekitar sungai/ kali Koyokop.

2. Pengumpulan data

Data yang dikumpulkan dalam penelitian ini adalah data primer dan data sekunder. Data primer diperoleh dari pengamatan langsung di lapangan, meliputi jenis-jenis tumbuhan obat dan pemanfaatannya. Data tersebut dikumpulkan dengan cara pengamatan terhadap jenis-jenis tumbuhan dan mengetahui pemanfaatannya dari masyarakat suku Mandobo melalui wawancara. Pengumpulan data melalui penjelajahan kawasan hutan dengan didampingi oleh seorang pengenal jenis dan memberi nama lokal.
Deskripsi tumbuhan tersebut dicatat dan tumbuhan tersebut diambil sampel guna pembuatan herbarium yang dibuat sebanyak tiga contoh. Data lain yang dibutuhkan dalam penelitian ini adalah data sekunder yang diperoleh dari instansi terkait berupa keadaan umum daerah termasuk iklim dan topografi.

\section{Variabel Pengamatan}

Variabel yang diamati dalam penelitian ini adalah :

Jenis tumbuhan yang dimanfaatkan terdiri dari nama ilmiah (famili dan spesies) dan nama lokal (bahasa Wambon), bagian tumbuhan yang digunakan terdiri dari akar, batang, kulit, daun, buah, bunga dan getah, manfaat dan cara mengolah, khasiat lain dari tumbuhan tersebut, pola transfer pengetahuan dan pola konservasi tradisional

\section{Pengolahan dan Analisis Data}

Data yang diperoleh diolah dan dianalisis secara deskriptif dan kemudian disajikan dalam bentuk tabulasi dan gambar atau foto.

\section{HASIL DAN PEMBAHASAN}

\section{Jenis Tumbuhan Yang Dimanfaatkan}

Pemanfaatan tumbuhan sebagai obat tradisional telah lama dilakukan oleh masyarakat suku Mandobo di Kampung Sokanggo. Pada umumnya masyarakat suku Mandobo yang mengenal jenis tubuhan obat berusia paling tua berumur 54 tahun. Berdasarkan hasil wawancara dan observasi lapang diketahui 25 jenis tumbuhan obat dari 20 famili yang terdiri dari berbagai tingkatan (rumput, pohon, perdu, herba liana dan terna) yang dimanfaatkan oleh suku Mandobo di Kampung Sokanggo Distrik Mandobo 
Tabel 1. Deskripsi botani tumbuhan, bentuk dan cara pengolahan yang dilakukan oleh masyarakat suku Mandobo di Kampung Sokanggo

\begin{tabular}{|c|c|c|c|}
\hline Spesies & Famili & $\begin{array}{c}\text { Bagian yang } \\
\text { dimanfaatkan }\end{array}$ & Cara Pengolahan \\
\hline Annona muricata & Annonaceae & Daun & $\begin{array}{l}\text { Daunnya diambil 3-4 helai kemudian direbus, setelah } \\
\text { mendidih airnya diminum }\end{array}$ \\
\hline Alstonia scholaris & Apocynaceae & Kulit & Kulitnya direbus lalu diminum airnya \\
\hline Agathis dammara & Araucariaceae & Kulit & $\begin{array}{l}\text { Kulitnya dikupas lalu dibersihkan setelah dibersikan } \\
\text { direbus kemudian diminum airnya }\end{array}$ \\
\hline Calamus sp. & Arecaceae & Pucuk & $\begin{array}{l}\text { Bagian pucuk tali rotan di diambil dengan cara } \\
\text { dipotong lalu dimakan }\end{array}$ \\
\hline Garcinia mangostana & Clusiaceae & Kulit & $\begin{array}{l}\text { Buahnya yang sudah masak diambil 1-2 lalu dimakan. } \\
\text { Daun diambil 3-4 lembar, ditumbuk dengan batu lalu } \\
\text { ditempelkan pada bagian yang luka }\end{array}$ \\
\hline Kalanchoe pinnata & Crassulaceae & Daun & $\begin{array}{l}\text { Daunnya di ambil kemudian dipanaskan di api lalu di } \\
\text { tempelkan pada bagian tubuh yang terasa sakit }\end{array}$ \\
\hline Momordicae charanntia & Cucurbitaceae & Daun & Daunnya dipetik lalu direbus dan minum airnya \\
\hline Jatropha curcas & Euporbiaceae & Getah & Getahnya diambil kemudian digosokan pada luka \\
\hline Casia alata & Fabanaceae & Daun & 20 lembar daun dikucak lalu digosok pada kulit \\
\hline Mimosa pudica & Fabaceae & Daun & $\begin{array}{l}5 \text { helai daun dipetik dan dicuci bersih lalu direbus } \\
\text { dengan air lalu diminum }\end{array}$ \\
\hline Flagellaria indica & Flagellariaceae & Getah & $\begin{array}{l}\text { Getanya diperoleh dengan cara dipotong batangnya } \\
\text { lalu ambil getahnya diteteskan pada mata }\end{array}$ \\
\hline Ficus septica & Moraceae & Daun & $\begin{array}{l}\text { Daunnya di panaskan di atas bara api lalu di } \\
\text { tempelkan pada bagian tubuh yang terasa sakit }\end{array}$ \\
\hline Ficus quercifolia & Moraceae & Kulit & Kulitnya dikupas lalu ditempel pada bagian gigitan \\
\hline Coleus sp. & Lamiaceae & Daun & $\begin{array}{l}\text { Daunnya di tumbuk lalu diremas kemudian airnya } \\
\text { diteteskan pada mata }\end{array}$ \\
\hline Orthosiphon aristatus & Lamiaceae & $\begin{array}{l}\text { Daun, bunga, } \\
\text { akar, }\end{array}$ & $\begin{array}{l}\text { Seluruh bagian tumbuhan direbus kemudian disaring } \\
\text { lalu diminum }\end{array}$ \\
\hline Psidium guajava & Myrtaceae & Daun & $\begin{array}{l}\text { Pucuk daun yang telah dipetik dicuci bersih lalu } \\
\text { dimakan }\end{array}$ \\
\hline Nepenthes sp. & Nepenthesceae & Kantong & $\begin{array}{l}\text { Kantong semar diambil yang didalamnya terisi air lalu } \\
\text { diteteskan pada telinga }\end{array}$ \\
\hline Piper betel & Piperaceae & Daun & $\begin{array}{l}\text { Ambil daun sirih hijau, panaskan hingga layu lalu } \\
\text { tempelkan pada luka }\end{array}$ \\
\hline Pometia coreaceae & Sapindaceae & Kulit & $\begin{array}{l}\text { Kulit matoa yang diambil adalah bagian dalam } \\
\text { kemudian ditempelkan pada bagian tubuh yang luka }\end{array}$ \\
\hline Smilax sp. & Smilaceae & Daun & $\begin{array}{l}\text { Daunnya dibungkus, dipanaskan kemudian diperas } \\
\text { dan diteteskan pada hidung }\end{array}$ \\
\hline Laportea indica & Urticaceae & Daun & $\begin{array}{l}\text { Daunnya digosokan pada bagian tubuh yang terasa } \\
\text { sakit }\end{array}$ \\
\hline Zingiber officinale & Zingaberaceae & Umbi & Umbi yang telah diambil dicuci bersih lalu dimakan \\
\hline Amomumn aculeactum & Zingiberaceae & Buah & Buahnya dipetik kemudian dicuci bersih lalu dimakan \\
\hline Curcuma domestica & Zingiberaceae & Umbi & $\begin{array}{l}\text { Umbinya diparut kemudian direbus lalu airnya } \\
\text { diminum }\end{array}$ \\
\hline Cymbopogon nardus & Zingiberaceae & Batang & $\begin{array}{l}\text { Ambil } 1 / 4 \text { batang sereh kemudian ditumbuk lalu } \\
\text { masukan dalam gigi yang lubang }\end{array}$ \\
\hline
\end{tabular}


sebagai obat tradisional. Jenis tumbuhan obat yang diperoleh dari hutan, kebun dan juga pekarangan rumah baik yang di introduksi dari hutan atau tumbuh secara liar. Jenis-jenis tumbuhan yang dimanfaatkan sebagai obat tradisional oleh masyarakat suku Mandobo Distrik Mandobo dapat dilihat pada tabel 1 . Secara botanis, famili dari jenis tumbuhan obat yang paling banyak dimanfaatkan oleh suku Mandobo berturut-turut adalah Zingiberaceae, Moraceae, Lamiacea. Sementara dari jenis tumbuhan obat paling banyak merupakan habitus pohon dan dijumpai disekitar pekarangan rumah.

\section{Bagian Yang Dimanfaatkan}

Bagian tumbuhan yang dimanfaatkan sebagai bahan obat oleh masyarakat suku Mandobo kampung Sokanggo terdiri dari getah, kulit batang, daun dan buah. Namun bagian tumbuhan yang paling banyak terlihat digunakan untuk menyembuhkan penyakit yaitu bagian daun. Tabel 1 menunjukkan bahwa bagian tumbuhan yang paling banyak dimanfaatkan sebagai obat berdasarkan jumlah jenis secara berurutan adalah daun sebanyak 12 jenis tumbuhan, selanjutnya bagian kulit sebanyak 5 jenis, sementara bagian umbi dan getah masing-masing sebanyak 2 jenis, sementara bagian buah dan batang masing-masing hanya 1 jenis. Daun paling banyak digunakan karena dalam pengambilan dan penemuannya tergolong mudah dan sederhana. Disamping itu khasiat dan kandungan komponen bioaktif dan senyawa kimia penting dalam pengobatan dominan berada pada bagian daun, dibandingkan pada bagian lain dari tubuh tanaman (Ramadhan dkk. 2014).

\section{Cara Mengolah}

Cara mengolah tumbuhan sebagai bahan obat berdasarkan pengetahuan masyarakat dibagi menjadi dua, yakni secara langsung dan melalui proses pengolahan. Secara langsung biasanya ketika ditemukan langsung dapat dimakan dan bagian yang biasanya dapat dimakan secara langsung ialah bagian pucuk, tunas muda, dan umbi. Namun sebagian besar dilakukan melalui proses memasak seperti direbus, dipanaskan di atas api, ditumbuk, dan dihancurkan. Masyarakat suku Mandobo banyak memanfaatkan tumbuhan dengan cara direbus dan dipanaskan di atas api. Tabel 1 Memperlihatkan bahwa cara mengolah tumbuhan obat yaitu lebih banyak dilakukan dengan cara direbus dengan jumlah spesies tumbuhan sebanyak 7 spesies. Kusumawati dan Yogeswara (2016) mengindikasikan bahwa proses perebusan cenderung melarutkan bahan bioaktif secara maksimal ke dalam air rebusan dan mempertahankan khasial kandungan bahan bioaktif pada daun yang direbus. Selain daun, bagian kulit batang tumbuhan juga biasanya direbus guna mendapatkan hasil ekstrak rebusan untuk selanjutnya diminum. Sementara untuk jenis getah-getahan, biasanya langsung digunakan dengan cara dioleskan pada luka atau bagian tubuh yang terasa sakit. Teknik yang sama juga dilakukan dengan olahan daun, baik dipanaskan atau dikunyah secara langsung dan dioleskan pada bagian yang luka atau terasa sakit seperti bisulan.

\section{Khasiat}

Berdasarkan informasi yang diperoleh dari responden, diketahui bahwa berbagai jenis tumbuhan yang dimanfaatkan sebagai alternatif obat untuk 
menyembuhkan beberapa penyakit seperti batuk, malaria, diare, serampah, penyakit kulit dan luka bakar, sengat dan terbelah. Dari klasifikasi penyakit yang disebutkan tersebut, dominan tipe penyakit yang umum diderita adalah jenis batuk dimana terdapat 4 jenis tumbuhan yang dapat dikonsumsi untuk meredahkan penyakit batuk dan terglolong paling umum. Selanjutnya setiap jenis tumbuhan yang telah disebutkan masing-masing memiliki khasiat yang dapat menyembukan atau memulihkan rasa sakit yang diderita oleh masyarakat Kampung Sokanggo. Dari deskripsi ini memperlihatkan kecenderungan pola ketergantungan masyarakat pada alamnya secara khusus jenis-jenis tumbuhan yang berkhasiat dalam pengobatan. Hampir sebagian besar penyakit umum yang diderita dapat disembuhkan berbasis pengetahuan etnomedis masyarakat setempat. Secara umum, ketergantungan masyarakat di sekitar hutan dengan sumber daya hutan dalam pengobatan telah banyak terlihat seperti yang dilaporkan oleh Batoro dan Siswanto (2017) pada komunitas lokal di daerah Malang, Jawa Timur. Lekitoo et al. (2017) juga mengindikasikan variasi jenis tumbuhan pegunungan seperti jenis pandanus dapat memiliki khasiat obat yang muncul berdasarkan pengetahuan lokal masyarakat secara turun temurun.

Selain sebagai alternatif tanaman obat, beberapa jenis tanaman juga digunakan untuk beberapa keperluan lain dalam keseharian hidup masyarakat di Kampung Sokanggo seperti diperuntukan untuk tanaman hias karena memiliki kesan dekoratif dan indah ketika dipandang seperti jenis Kalanchoe sp. Selain itu digunakan juga sebagai pelengkap bumbu masak seperti jenis Zingiber officinalis. Sementara guna kebutuhan kayu, maka jenis Alstonia scolaris dan Ficus sp. Dapat digunakan sebagai pelengkap konstruksi pembangunan tempat tinggi bagi mayarakat Mandobo di Kampung Sokanggo.

\section{Pola Tranfer Pengetahuan}

Pola diartikan sebagai cara atau jalan melakukan sesuatu. Transfer diartikan sebagai pemindahan atau pengalihan hak pada orang lain. Pengetahuan diartikan sebagai segala sesuatu yang diketahui berkenan dengan keahlian atau kepandaian (Departemen Pendidikan Nasional 2008). Secara umum pola transfer pengetahuan diartikan sebagai cara pemindahan atau pengalihan segala sesuatu yang di ketahui kepada orang lain. Pengetahuan tentang tumbuhan obat sudah ada sejak dahulu melalui pengalaman yang berlangsung lama telah menjadi tradisi suatu daerah, sehingga hanya dikembangkang dari generasi ke generasi. Pola pemanfaatan yang dimiliki oleh orang tua (ayah atau ibu) diwariskan pada anak-anak terutama anak yang paling sering diikut sertakan dalam membatu pekerjaan orang tua. Pola transfer pengetahuan lokal oleh Masyarakat Suku Mandobo di Kampung Sokanggo tidak hanya diturunkan ke anak kandung, tetapi dapat juga ditransfer kepada anak angkat atau keponakan maupun cucu dengan satu syarat yaitu memiliki hubungan kekerabatan yang dekat.

\section{Pola Konservasi Tradisional}

Pola konservasi tradisional yang dilakukan oleh masyarakat suku Mandobo di Kampung Sokanggo terhadap kelestarian jenis-jenis tumbuhan obat tradisional adalah menanam jenis jenis tumbuhan obat disekitar halaman 
rumah, disisi lain masyarakat belum mengetahui tentang pelestarian, selain itu dalam pemanfaatan sebagai obat tidak pernah dilakukan dengan menebang seluruh pohon tetapi cukup dipungut bagian tumbuhan yang akan dijadikan obat.

\section{DAFTAR PUSTAKA}

Batoro J dan Siswanto D. 2017. Ethnomedical survey of plants used by local society in Poncokusumo district, Malang, East Java Province, Indonesia. Asian Journal of Medical and Biological Research, 3 (2): 158167.

Cabuy RL, Marwa J, Manusawai J and Rahawarin YY. 2012. Non-woody plant species of Papuan island forest, a sustainable source of food for the local communities. Indian Journal of Traditional Knowledge, 11 (4): 586592.

Departemen Pendidikan Nasional. 2008. Kamus bahasa Indonesia. Pusat Bahasa Departemen Pendidikan Nasional, Jakarta.

Kusumawati IW dan Yogeswara IBA. 2016. Kapasitas antioksidan dan antibakteri loloh sembung (Blumea balsamifera) berdasarkan metode ekstraksi. Trad. Med. Jurnal, Vol 21 (3): 143-148.

Lekitoo K, Peday HFZ, Panambe N and Cabuy RL. 2017. Ecological and ethnobotanical facet of 'Kelapa Hutan' (Pandanus spp.) and perspectives towards its existence and benefit. International Journal of Botany, 13: 103-114.

Muller K. 2005. Keanekaragaman hayati tanah Papua. Universitas Negeri Papua dan Dinas Pendidikan dan Pengajaran Provinsi Papua.

Ramadhan BC, Aziz SA dan Ghulamadhi M. 2015. Potensi kadar bioaktif yang terdapat pada daun kepel (Stelechocarpus burahol). Bul. Littro, Vol 26 (2): 99-108.

Wowor H, Liando DM dan Rares J. 2016. Pelayanan kesehatan di pusat kesehatan masyarakat (PUSKESMAS) Amurang Timur Kabupaten Minahasa Selatan. Jurnal Ilmu Sosial \& Pengelolaan Sumberdaya Pembangunan Edisi XX (Januari Februari 2016). Vol 3: 103-122. 